\title{
Manufacturing of High Quality Titanium Thin Foil by Electrodeposition Route
}

\author{
Daisuke Suzuki, Haruka Yamamoto, Matsuhide Horikawa and Hideki Fujii
}

TOHO TITANIUM CO., LTD, Chigasaki-City Kanagawa, Japan

\begin{abstract}
$\underline{\text { Abstract }}$
To challenge the significant reduction of manufacturing cost of Ti thin sheet or foil in the future, manufacturing of Ti foil by electrodeposition route was studied with emphasizing on factors affecting quality of the foil and separability from Mo cathode. Current density was one of the strong factors affecting soundness of deposited Ti foil and its separability from the cathode. Electrolyte bath temperature also affected soundness and separability of deposited Ti foil. Separability was closely related to interdiffusion distance of $\mathrm{Ti}$ and Mo, that is, shorter diffusion distance, which was brought by low temperature and low current density, led to good separability as well as good surface quality. By reflecting above knowledge, post card size Ti foil of around $0.1 \mathrm{~mm}$ in thickness was successfully obtained. It had good quality and could be separated from the cathode by hand. O and Fe contents were drastically decreased by this process.
\end{abstract}

\section{Introduction}

Titanium foil is used for a variety of applications by making use of excellent properties such as high corrosion resistance, lightweight, good formability and relatively high strength, and application range is now expanding. For example, they are recently used for fuel cell parts installed in fuel cell vehicles, 
speaker diaphragm and corrosion protection films for steel structures, etc. ${ }^{(1-3)}$ However, high manufacturing cost of titanium thin gauge sheets or foils is one of the obstacles hindering the rapid expansion of their application range. To overcome the issue, direct electrodeposition of titanium thin foils in molten salt electrolytes has been studied, in which a series of complicated processes including melting, rolling and annealing can be excluded and low cost materials such as scraps and low grade titanium sponge can be used as starting raw materials.

The concept was originally proposed by Tokumoto et al. ${ }^{(4)}$ in 1950 s, and highly pure thin titanium films with extremely low impurity contents have been obtained ${ }^{(4-6)}$ so far although they are limited in size. However, to be used as commercial products, a lot of issues are needed to be solved. For instance, the foils have to have smooth surfaces without severe roughness, and defects such as pits should be eliminated. In addition, broader area, preferably more than A4-size, is desired. Furthermore, it should be noted that separability of deposited Ti foil from the electrode is quite important for this process to be industrialized.

From those points of view, factors affecting quality of the foil and separability from the cathode were closely investigated and manufacturing of high quality, broad (post card size) Ti foils which can easily be separated from the cathode was challenged.

\section{Experimental procedures}

Fig. 1 shows a device used in this study. Electrolyte used was a mixture of $\mathrm{KCl}, \mathrm{NaCl}$ and $\mathrm{MgCl}_{2}$ with some amount of $\mathrm{TiCl}_{2}$, where ratio of cations were $\mathrm{Mg}: \mathrm{Na}: \mathrm{K}: \mathrm{Ti}=39: 30: 25: 6$. The electrolyte was placed in the vessel made of $\mathrm{Ni}$, and a cathode made of Mo and an anode made of Ti, which was the source of $\mathrm{Ti}^{2+}$, were immersed in the electrolyte. To obtain wider area of the cathode, Mo foil was deformed to cylindrical shape and wrapped around Ni cylinder connected with the power supply. To respond to this shape of the cathode, JIS Class 2 Ti tube or ring connected with the power supply was used as the anode. Distance between the electrodes was $30 \mathrm{~mm}$. Experiments were conducted in Ar gas atmosphere.

After heating the electrolyte to the prescribed temperature $\left(520\right.$ and $\left.700{ }^{\circ} \mathrm{C}\right)$, pulse current was applied, in which electricity flew for $1.5 \mathrm{~s}$ and was cut off for $1.5 \mathrm{~s}$.

Parameters and conditions used in the study including current density were summarized in Table 1. 
Table 1 Conditions employed in electrodeposition experiments.

\begin{tabular}{|l|l|}
\hline Anode & Ring shaped Ti (JIS Class 2) \\
\hline Cathode & Mo foil, wrapped around Ni cylinder \\
\hline Distance between electrodes & $30 \mathrm{~mm}$ \\
\hline Electrolytic bath temperahure & $520,700^{\circ} \mathrm{C}$ \\
\hline Electrolytic area & $70,150 \mathrm{~cm}^{2}$ \\
\hline Current density & $0.05 \sim 0.40 \mathrm{~A} / \mathrm{cm}^{2}$ \\
\hline Energization time & $27 \sim 268 \mathrm{~min}$ \\
\hline
\end{tabular}

After the electrodeposition experiments, deposited Ti was taken out of the vessel together with the cathode Mo foil and washed with pure water. Evaluation of the deposited Ti was conducted basically for pairs of the deposited Ti and Mo foil.

SEM observations for surfaces and cross sections as well as EPMA analyses for cross sections were conducted, and $\mathrm{O}$ and $\mathrm{Fe}$ contents in the deposited $\mathrm{Ti}$ were measured. In addition, separability was evaluated by stripping off the deposited Ti from the Mo foil by hand.

Based on the EPMA analyses for the cross section of Ti/Mo pairs, interdiffusion distance of Ti and Mo was measured. Fig. 2 shows a method for interdiffusion distance measurement. A pair of the deposited Ti and the Mo cathode is regarded as a kind of a diffusion couple, in which one element diffuses to the other material, that is, Ti diffuses into the Mo cathode and Mo diffuses into the deposited Ti. Interdiffusion distance was defined as the distance between the position where concentration of $\mathrm{Ti}$ started decreasing in the deposited $\mathrm{Ti}$ and the position where Ti concentration reached zero in the Mo cathode. For example, interdiffusion distance was $5.2 \mu \mathrm{m}$ when EMPA data shown in Fig. 2 were obtained, in which the origin was taken at the position where concentration of Ti started decreasing. In the current study, Mo and Ti showed similar diffusion distance, and the distance Ti diffused and the distance Mo diffused were almost the same. 


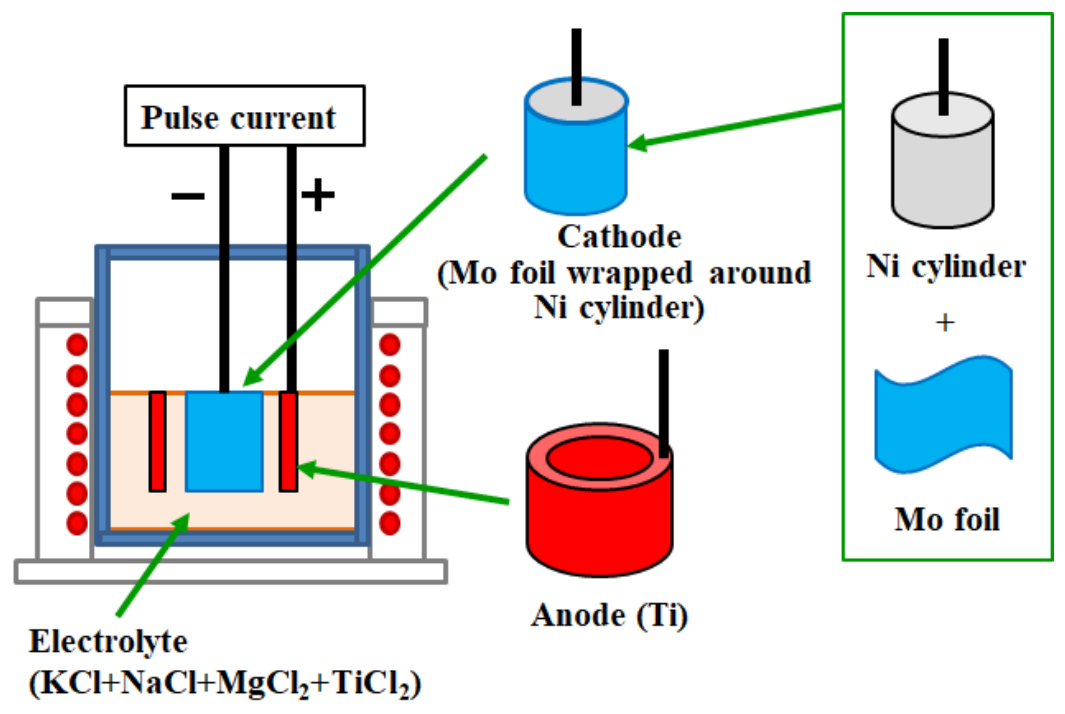

Fig. 1 Schematic representation of experimental device used.

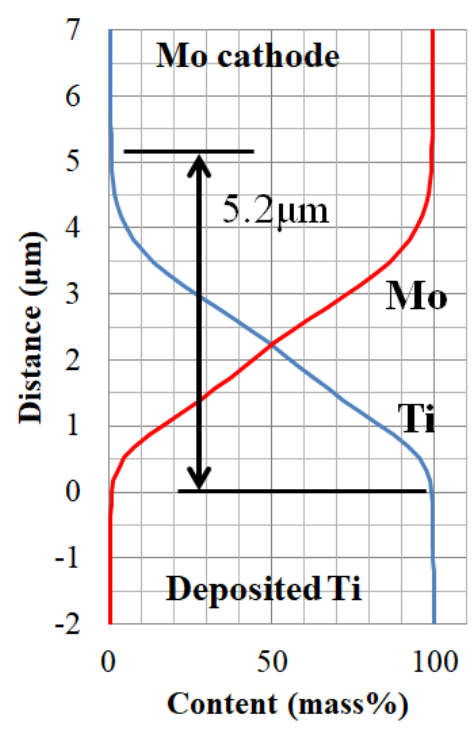

Fig. 2 Example of result of EPMA analysis for cross section of a pair of deposited Ti and Mo cathode. Interdiffusion distance was $5.2 \mu \mathrm{m}$. The origin of the vertical axis was taken at the 
position where concentration of $\mathrm{Ti}$ started decreasing in the deposited $\mathrm{Ti}$.

\section{3. $\underline{\text { Results }}$}

\subsection{Effect of current density}

Table 2 shows the results of a series of experiments where current density was varied from 0.05 to $0.40 \mathrm{~A} / \mathrm{cm}^{2}$ under the condition of constant electrolyte bath temperature at $520{ }^{\circ} \mathrm{C}$ and constant electrolytic area of $70 \mathrm{~cm}^{2}$ (around A7 size). In those experiments, the same electricity was applied to obtain the same thickness, meaning that the energization time was different as shown in Table 2, it is shorter in the experiments with higher current density. Thickness of the deposited Ti was around 0.1 $\mathrm{mm}$ in all experiments conducted.

As shown in Table 2, in the experiments with the current density lower than $0.11 \mathrm{~A} / \mathrm{cm}^{2}$, separability was good and actually Ti foil was successfully stripped off from the Mo cathode. In addition, obtained Ti foils had smooth surface on which open holes and dendritic deposition, which increased surface roughness, were hardly observed.

Meanwhile, in the experiments with the current density higher than $0.22 \mathrm{~A} / \mathrm{cm}^{2}$, separability was poor and the deposited Ti could not be stripped off from the Mo cathode by hand. Surfaces of the deposited Ti were not smooth due to the marked dendritic deposition.

Table 2 Effect of current density on quality of deposited Ti and separability from Mo cathode. 


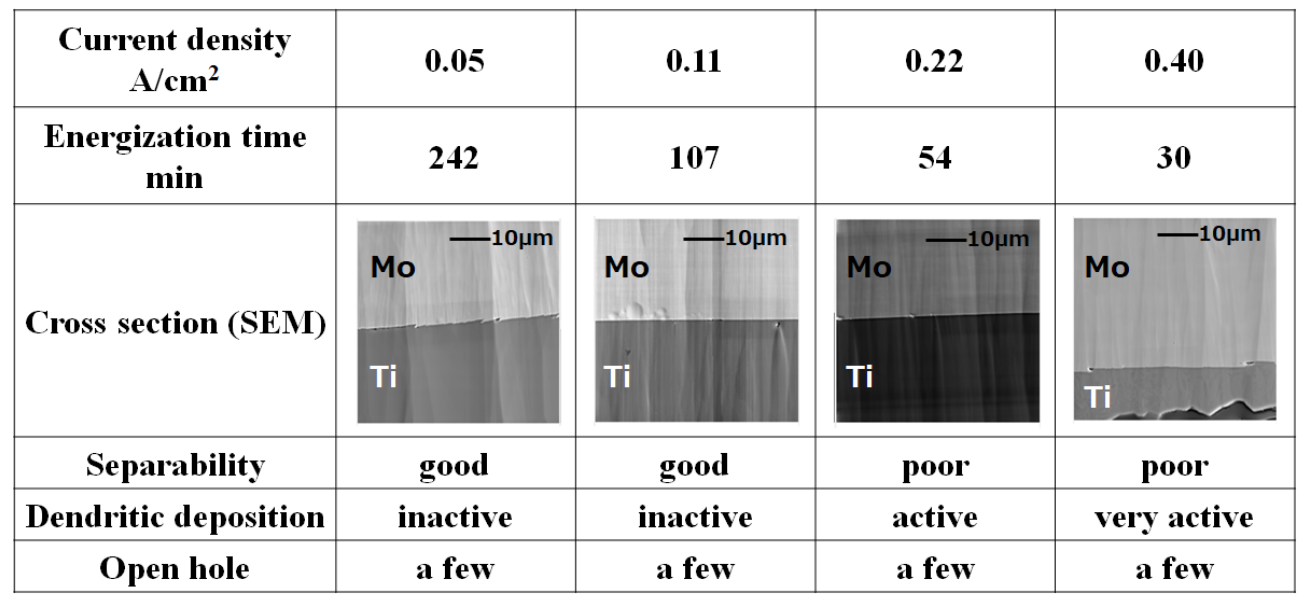

In Table 3, the result of an experiment in which current density was changed from 0.11 to $0.22 \mathrm{~A} / \mathrm{cm}^{2}$ on the way of electrodeposition is summarized with the results of the experiments with constant current density $\left(0.11\right.$ and $\left.0.22 \mathrm{~A} / \mathrm{cm}^{2}\right)$ which are shown also in Table 2. Other parameters were the same as those in the experiments shown in Table 2.

Although sound Ti foil with smooth surface and good separability was obtained in the experiment with the constant current density of $0.11 \mathrm{~A} / \mathrm{cm}^{2}$, dendritic deposition became active and good separability was lost by raising the current density to $0.22 \mathrm{~A} / \mathrm{cm}^{2}$ on the way of electrodeposition. It suggests that the high current density enhances dendritic deposition and aggravates separability of the deposited Ti from the Mo cathode.

Table 3 Effect of current density change during electrodeposition on quality of deposited Ti and separability from Mo cathode. For comparison, results of the experiments with constant current density (shown in Table 2) are shown again. 


\begin{tabular}{|c|c|c|c|}
\hline $\begin{array}{c}\text { Current density } \\
\qquad \mathbf{A} / \mathbf{c m}^{2}\end{array}$ & $0.11 \rightarrow 0.22$ & 0.11 & 0.22 \\
\hline $\begin{array}{l}\text { Energization time } \\
\text { min }\end{array}$ & $\begin{array}{c}67 \\
\left(0.11 \mathrm{~A} / \mathrm{cm}^{2}, 27 \mathrm{~min}\right. \\
\left.+0.22 \mathrm{~A} / \mathrm{cm}^{2}, 40 \mathrm{~min}\right) \\
\end{array}$ & 107 & 54 \\
\hline \multirow{2}{*}{ Cross section (SEM) } & & Mo $-10 \mu \mathrm{m}$ & Mo $-10 \mu \mathrm{m}$ \\
\hline & $-10 \mu \mathrm{m}$ & $\mathrm{Ti}$ & $\mathrm{Ti}$ \\
\hline Separability & poor & good & poor \\
\hline Dendritic deposition & active & inactive & active \\
\hline Open hole & a few & a few & a few \\
\hline
\end{tabular}

\subsection{Effect of bath temperature}

Table 4 shows the result of an experiment where electrolyte bath temperature was $700{ }^{\circ} \mathrm{C}$. Current density was $0.11 \mathrm{~A} / \mathrm{cm}^{2}$ and other parameters were the same as those in the experiments shown in Table 2. Here, the results of the experiments at $520^{\circ} \mathrm{C}$, which are shown in Table 2 and 3, are shown here again for comparison.

Dendritic deposition became active and good separability, which was obtained in the experiment conducted at $520{ }^{\circ} \mathrm{C}$ and with $0.11 \mathrm{~A} / \mathrm{cm}^{2}$, was lost by raising temperature to $700{ }^{\circ} \mathrm{C}$, suggesting that dendritic deposition is enhanced and separability of the deposited Ti from the Mo cathode is reduced at high temperature.

Table 4 Effect of electrolyte bath temperature on quality of deposited Ti and separability from Mo cathode. Current density was $0.11 \mathrm{~A} / \mathrm{cm}^{2}$. 


\begin{tabular}{|c|c|c|}
\hline $\begin{array}{l}\text { Electrolyte bath } \\
\text { temperature }{ }^{\circ} \mathrm{C}\end{array}$ & 520 & 700 \\
\hline $\begin{array}{c}\text { Energization time } \\
\text { min }\end{array}$ & 107 & 107 \\
\hline Cross section (SEM) & $\begin{array}{l}\text { Mo }-10 \mu \mathrm{m} \\
\text { Ti }\end{array}$ & $\begin{array}{l}\text { Mo }-10 \mu \mathrm{m} \\
\mathrm{Ti}\end{array}$ \\
\hline Separability & good & poor \\
\hline Dendritic deposition & inactive & very active \\
\hline Open hole & a few & a few \\
\hline
\end{tabular}

\subsection{Diffusion distance of Ti in the pair of deposited Ti and Mo cathode}

Interdiffusion distance measured with the method explained in the "Experimental procedures", based on the results of EPMA analyses for the cross section of Ti/Mo pairs, is summarized in Fig.3.

It is quite clear that the separability of the Ti/Mo pairs is closely related to the diffusion distance of Ti. In the case of longer diffusion distance, which was brought by high current density and high electrolyte bath temperature, separability became poor. It means that the separability is reduced when the alloying of Mo-Ti progresses.

From the information in Fig.3, it is considered that the threshold of poor/good separability was around $4 \mu \mathrm{m}$ of diffusion distance in the pair of the Mo cathode and the deposited Ti. If diffusion distance is shorter than $4 \mu \mathrm{m}$, the deposited Ti foil can probably be stripped off from the Mo cathode by hand. 


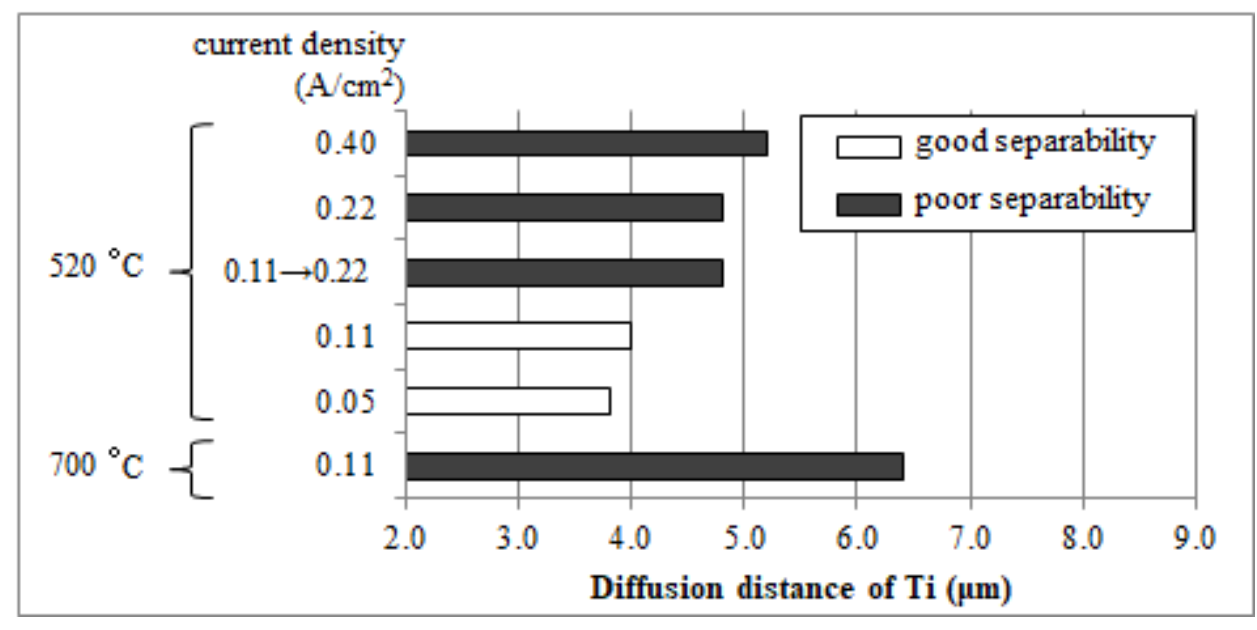

Fig. 3 Diffusion distance of $\mathrm{Ti}$ in the pair of Mo cathode and deposited $\mathrm{Ti}$.

\subsection{Manufacturing of Postcard Size Ti foil}

Based on the knowledge obtained in the experiments described above, manufacturing of Ti foils having wider area was challenged.

Electrodeposition conditions were basically the optimum ones with which high quality Ti foils were obtained in the previously introduced experiments : current density was $0.11 \mathrm{~A} / \mathrm{cm}^{2}$, bath temperature was $520{ }^{\circ} \mathrm{C}$. However, to obtain broader area, the area of the cathode also has to be broader. In this trial, Mo foil of $150 \times 100 \mathrm{~mm}$ in size $\left(150 \mathrm{~cm}^{2}\right)$ was used as a cathode.

An appearance of the cathode just after taken out of the bath is shown in the left hand photograph in Fig.4. After the cathode was rolled out to flat manner and the edges were slightly trimmed, Ti foil was stripped off by hand from the Mo cathode. In the right hand photograph in Fig.4 is shown the appearance of the separation process.

Fig.5 is the appearance of the separated Ti foil. Although some wrinkles formed due to the insufficient skill of the separation process, quite high quality Ti foil was obtained. When it was held to 
a light source, no leak of the light was detected, suggesting that there was no through hole in the foil. The size of the foil was $150 \times 90 \mathrm{~mm}$, close to the post card size, and thickness was around $0.1 \mathrm{~mm}$.

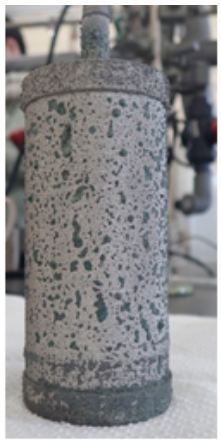

Cathode after electrodeposition

\section{Rolled} out
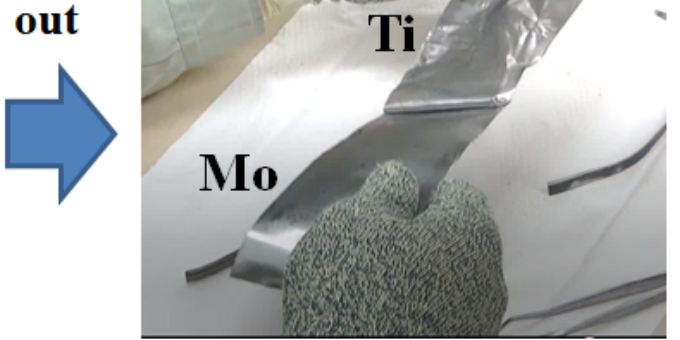

\section{Separation of deposited Ti foil from Mo foil cathode by hand}

Fig. 4 Cathode just after taken out of electrolyte bath (left) and separation process of Ti foil from cathode (right).

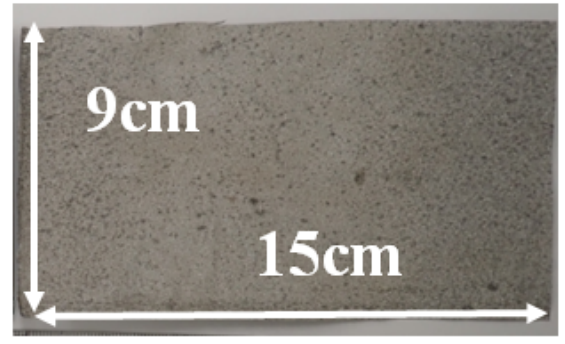

Bath side view

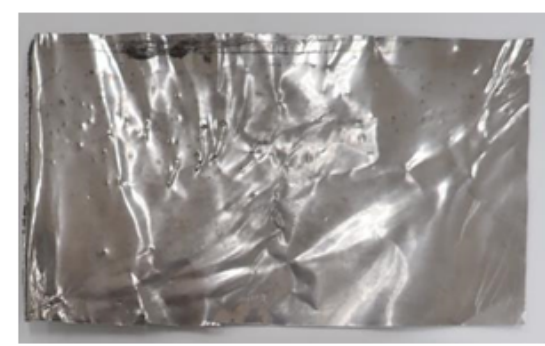

Cathode side view

Fig. 5 Appearance of post card size Ti foil manufactured by electrodeposition route.

Fig. 6 show closer look of the obtained Ti foil by electrodeposition route. Bath side surface was not even microscopically and a few dendritic particles were observed. However, it will be flattened by slight cold rolling. Due to the unevenness of the bath side surface, thickness of the foil varied from 70 
to $120 \mu \mathrm{m}$, while mean thickness was $100 \mu \mathrm{m}$. The difference of the thickness will be reduced again by slight cold rolling.
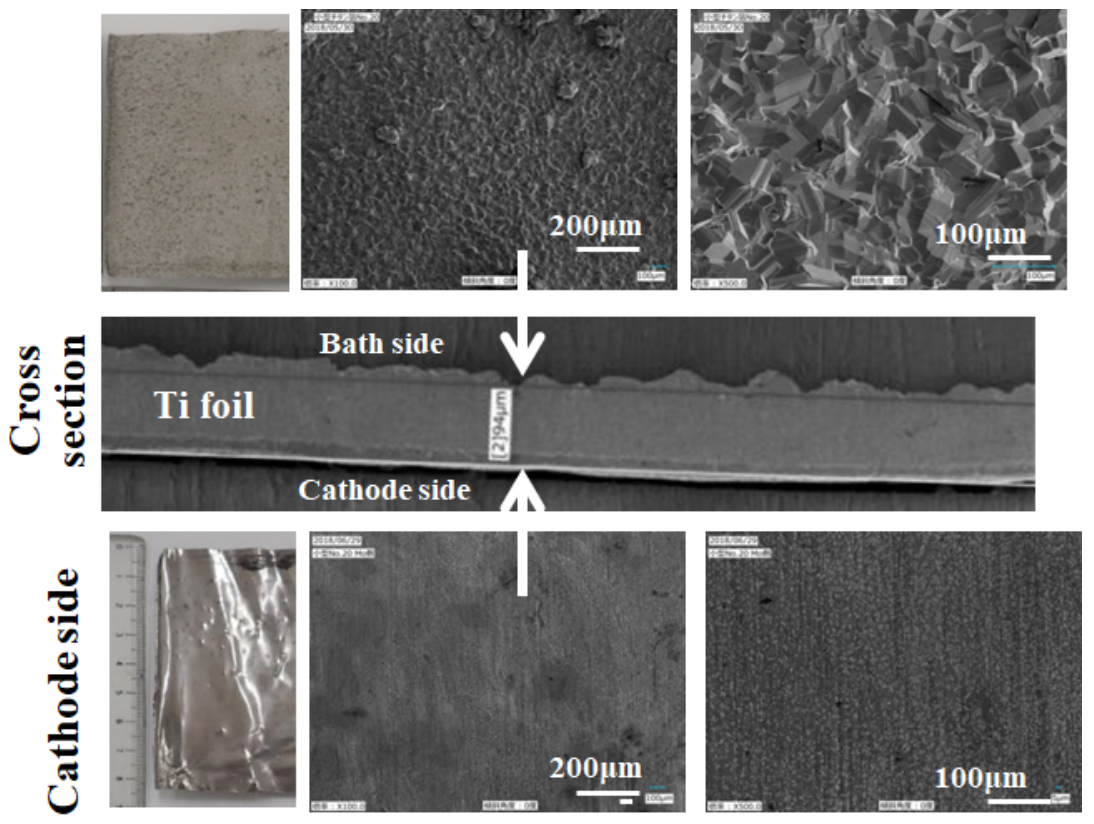

Fig. 6 SEM observation for cross section and surfaces of obtained post card size Ti foil.

$\mathrm{O}$ and Fe contents in the foil were listed in Table 5. As the electrodeposition process is the electrorefining process, both $\mathrm{O}$ and $\mathrm{Fe}$ contents were drastically reduced from those in the starting material used as the anode (JIS Class 2 pure Ti). In this respect, the obtained Ti foil is high purity Ti, and it indicates that low-grade sponge titanium and scraps of wrought titanium can be used for the anode, which will contribute to further reduction of the production cost when this process is industrialized.

Table 5 Impurities in Ti foil manufactured by electrodeposition. 


\begin{tabular}{|c|c|c|}
\multicolumn{2}{c}{} & \multicolumn{3}{c|}{ (mass ppm) } \\
\hline & 0 & Fe \\
\hline Starting material (Anode, JIS Class 2 Ti) & 700 & 600 \\
\hline Manufactured Ti foil & 185 & 6 \\
\hline
\end{tabular}

\section{Discussion}

As mentioned above, high quality Ti foil having good separability from the cathode was obtained by electrodeposition route by optimizing the manufacturing parameters. However, it has not been made clear why current density increases interdiffusion distance in the Ti (deposited material)-Mo(cathode) pair and affects separability of the deposited Ti from the Mo cathode.

Diffusion distance depends on temperature and time, that is, higher temperature and/or longer diffusion time lead to longer diffusion distance. However, the results of the experiments conducted at $520^{\circ} \mathrm{C}$, which are shown in Table 2 and Fig.3, clearly indicate that shorter electrodeposition time leads to longer diffusion distance. It means that higher current density increases the temperature near the boundary of the deposited Ti and the Mo cathode. Masumoto et al. ${ }^{(7)}$ investigated the interdiffusion of Mo and Ti using Ti-Mo diffusion couples. In that study, diffusion distance at $800^{\circ} \mathrm{C}$ for $30 \mathrm{~min}$ was at most $3 \mu \mathrm{m}$ (Ti diffused to Mo side by approximately $2 \mu \mathrm{m}$ and Mo diffused to Ti side by about $1 \mu \mathrm{m}$ ). Meanwhile, in the current study, diffusion distance was 3.8 to $5.2 \mu \mathrm{m}$ at $520^{\circ} \mathrm{C}$ for 60 to $120 \mathrm{~min}$, which is extraordinary long considering the temperature difference between the two experiments, 800 and $520^{\circ} \mathrm{C}$.

As the diffusion of Mo in the $\alpha$ phase of Ti is quite sluggish, there was no diffusion data available. Although it may not be correct, diffusion distance at 520,700 and $800{ }^{\circ} \mathrm{C}$ was estimated using the following diffusion data in the $\beta$ phase by extrapolating to lower temperatures :

$$
\mathrm{Do}=8 \cdot 10^{-7} \mathrm{~m} / \mathrm{s}, \mathrm{Q}=180 \mathrm{~kJ} / \mathrm{mol}^{(8)}
$$

Here, it is assumed that diffusion distance of Ti in Mo was 2 to 4 times longer than that of Mo in Ti. This assumption is based on the results by Masumoto et al. ${ }^{(7)}$ and also the results of EPMA analyses in this study. 
Table 6 Estimated interdiffusion distance in Ti/Mo diffusion couples. Estimation was conducted using the diffusion data of Mo in the $\beta$ Ti phase ${ }^{(8)}$ and assuming that diffusion distance of Ti in Mo is 2 to 4 times larger than that of Mo in Ti.

\begin{tabular}{|ll|l|}
\hline $520^{\circ}$ & $\mathrm{C}, 60 \mathrm{~min}$ & $0.015-0.025 \mu \mathrm{m}$ \\
\hline $520^{\circ}$ & $\mathrm{C}, 120 \mathrm{~min}$ & $0.021-0.035 \mu \mathrm{m}$ \\
\hline $700^{\circ}$ & $\mathrm{C}, 120 \mathrm{~min}$ & $0.696-1.159 \mu \mathrm{m}$ \\
\hline $800^{\circ}$ & $\mathrm{C}, 30 \mathrm{~min}$ & $1.469-2.448 \mu \mathrm{m}$ \\
\hline
\end{tabular}

Estimated diffusion distance is shown in Table 6. Although higher diffusivity data in the $\beta$ phase were used, diffusion distance at 520 and $700{ }^{\circ} \mathrm{C}$ was quite short compared to the experimental results shown in Fig.3. Meanwhile, diffusion distance at $800{ }^{\circ} \mathrm{C}$ for $30 \mathrm{~min}$ is close to the results (less than 3 $\mu \mathrm{m})$ by Masumoto et al.

This estimation strongly suggests that electric current increases the temperature at the vicinity of the boundary between the deposited Ti and the Mo electrode.

For now, it has not been made clear how electric current affects temperature. There are various factors which should be investigated. Resistance heating by precipitated Ti and Mo electrode is one of them. In this case, alloying of Mo and Ti may promote the resistance heating because alloys generally have higher electric resistance compared to pure metals. Pulse current may increase temperature. When high electric current is instantaneously applied, current distribution may be biased and quite high current may concentrate to small area, which leads to temperature rise. Once temperature rises, alloying is enhanced and temperature raise may be accelerated.

\section{Conclusions}

Manufacturing of Ti foil by electrodeposition route was investigated with emphasizing on factors affecting quality of the foil and separability from the cathode. Obtained results are as follows:

1. Current density was one of the strong factors affecting soundness of deposited Ti foil and its separability from Mo cathode.

2. Electrolyte bath temperature also affected soundness and separability. 
3. Separability was closely related to interdiffusion distance of Ti and Mo. Shorter diffusion distance, which was brought by low temperature and low current density, led to good separability and also higher surface quality of the foil.

4. Post card size Ti foil of around $0.1 \mathrm{~mm}$ in thickness was successfully obtained. It had relatively smooth surface and no conspicuous defect. It could be separated from the cathode by hand.

5. $\mathrm{O}$ and $\mathrm{Fe}$ contents were drastically decreased by electrodeposition process.

\section{Acknowledgement}

This work was conducted as a part of the project "Research and Development on Innovative Structural Materials" by the New Energy and Industrial Technology Development Organization (NEDO).

\section{7. $\underline{\text { References }}$}

[1] S.Matsumoto and H.Kita : NSSMC Tech. Rep., No.106 (2014), 114

[2] M.Tokita, M.Sasage and T.Takechi : ibid, 9

[3] M.Niinomi and K.Kagami : Ti-2015 Proc. $13^{\text {th }}$ World Conf. on Ti, (2016), 27

[4] S.Tokumoto, E.Tanaka and K.Ogisu : JOM, 27(1975), 18

[5] D.wei, R.Ichino, M.Okido and T.Oki : Hyoumengijutu, 44(1993), 3 (in Japanese)

[6] K.Funatsu, Y.Yamada, A.Kishimoto and T.Uda : Shigensozai(Web), (2017), ROMBUNNO.3401-0904(WEB ONLY) (in Japanese)

[7] H.Masumoto, K.Nishio, A.Asada, S.Mukae, M.Katoh and N.Hatanaka : J. Jpn. Weld. Soc., 10 (1992), 359 (in Japanese)

[8] G.B.Gibbs, D.Graham and D.H.Tomlin : Phil.Mag., 8 (1963), 1269 